\title{
Neuroaxial anesthesia caused paraplegia: a case report
}

\author{
Luis David Cortés-Badillo", Agustín Reyes-Gutiérrez ${ }^{1}$, Óscar Gómez-Chacón', \\ Luis David Olivera-León ${ }^{2}$, Elsy Daniela Olivera-León ${ }^{3}$, Juan José Granados-Romero" ${ }^{4}$, \\ Baltazar Barrera-Mera ${ }^{5}$, Rodrigo Banegas-Ruiz ${ }^{6}$, José Juan Vargas-Morales ${ }^{5}$, \\ Elvira Barrera-Calva ${ }^{5}$, Francisco Fabián Gómez-Mendoza ${ }^{7}$, Carlos Rubén Baca-Domínguez ${ }^{8}$, \\ Emilio Pérez Ortega9 ${ }^{9}$, Rodrigo A. Mendoza-Aceves ${ }^{10}$, \\ Mariana del Carmen Radilla-Flores' ${ }^{11}$, Nelson Niels Espinosa Queb"1, \\ Alejandro Ángel Corona Figueroa ${ }^{11}$, Bruno Andrés Salazar Trujillo11, \\ Mario Gutiérrez-Hernández ${ }^{12}$, Alan Isaac Valderrama-Treviño ${ }^{12} *$
}

\author{
${ }^{1}$ Department of Anesthesiology, PEMEX General Hospital, Ciudad del Carmen, Mexico \\ ${ }^{2}$ Department of Clinical Research. Center for Clinical Studies. Houston, Texas \\ ${ }^{3}$ Department of General Medicine, Autonomous University of Campeche, Mexico \\ ${ }^{4}$ Department of Surgery, ${ }^{5}$ Department of Physiology Faculty of Medicine, UNAM, CDMX, Mexico \\ ${ }^{6}$ Department of Traumatology, ${ }^{8}$ Department of Hand Surgery and Microsurgery, Rehabilitation Hospital, Luis Guillermo \\ Ibarra Ibarra, CDMX, Mexico \\ ${ }^{7}$ Department of Hand Surgery Central Military Hospital, CDMX, Mexico \\ ${ }^{9}$ Faculty of Medicine, UNAM, CDMX, Mexico \\ ${ }^{10}$ Department of Anesthesiology, Angeles del Pedregal Hospital. CDMX, Mexico \\ ${ }^{11}$ Department of Plastic Surgery, CENIAQ, CDMX, Mexico \\ ${ }^{12}$ Department of Surgery, Central North Hospital PEMEX, CDMX, Mexico
}

Received: 20 April 2021

Accepted: 07 May 2021

*Correspondence:

Dr. Alan Isaac Valderrama-Treviño,

E-mail: alan_valderrama@hotmail.com

Copyright: (c) the author(s), publisher and licensee Medip Academy. This is an open-access article distributed under the terms of the Creative Commons Attribution Non-Commercial License, which permits unrestricted non-commercial use, distribution, and reproduction in any medium, provided the original work is properly cited.

\section{ABSTRACT}

Patients who undergo; anesthesia, neuraxial analgesia, or some type of neuraxial blockage are exposed to multiple complications. 33-year-old male patient, suffers a femur fracture with a long oblique trace causing pain and functional limitation for movements. Surgical resolution is determined using neuraxial block at L2-L3 level, and intravenous sedation. During his postoperative follow-up, a decrease in strength was confirmed in the lower limbs with 0/5 on the Daniels scale, $100 \%$ sensitivity without sphincter control, steroids were prescribed along with magnetic resonance imaging and a neurosurgical evaluation was requested. The MRI shows bulging of the fibrous annulus that obliterates the epidural fat and makes contact with the thecal sac in the L5-S1 intervertebral disc level. The neurosurgery service prescribes rehabilitation sessions at home, electrostimulation and neuropathic medications. Patient was discharged with rehabilitation sessions at home and medical treatment. In his last consultation, an evaluation from the psychiatry department was requested for ideas of disability, hopelessness, fantasies of death without a suicide plan related to limitations and loss of functionality. Patient does not return to external follow-up, cannot be located.

Keywords: Neuroaxial anesthesia, Paraplegia, Neuraxial block, Neuraxial anesthesia complications, Spinal cord injuries, Non-reversible paraplegia 


\section{INTRODUCTION}

Patients who undergo; anesthesia, neuraxial analgesia, or some type of neuraxial blockage are exposed to multiple complications. Some of these deleterious events are indirectly related to the anesthesia technique and still others are produced by the anesthetic procedure itself or by the injected drugs. ${ }^{1}$ The first patient who received spinal anesthesia was dosed with $15 \mathrm{mg}$ of $0.5 \%$ cocaine through a trocar 14 , developing a severe headache shortly after and accounting for the first complication described in neuraxial anesthesia. Researcher Dr. Bier and his collaborator Hildenbrandt also suffered from this neurological complication when they anesthetized each other. ${ }^{2}$ The blood supply to the medula is given by 3 arterial systems that derive from the aortic arch and thoracic aorta. The anterior spinal artery is a continuation of the Adamkiewicz artery, responsible for suppling blood to the lumbar thickening of the spinal cord and the medullary cone. The middle sector of the medulla is irrigated by the thoracic radicular artery, which has some collaterals of the intercostal arteries, direct branches of the aorta. The vertebral arteries develop the cervical radicular artery that supplies blood to the medullary cervical sector, including the thickened portion. The anterior spinal artery provides $75 \%$ of the spinal blood supply, the rest is provided by the posterior spinal arteries. It is important to remember that lumbar medullary thickening is where the nerves of the lumbosacral plexus originate, which command the motor skills of the lower extremities and determine sphincter control. Hence the importance of always maintaining spinal vascular flow to its full extent. The Adamkiewicz artery is a unique vessel, its changin anatomy is frequently is mentioned as an important factor in the development of severe neurospinal complications related or not to neuraxial anesthesia. For example, having atheroma plaques will compromise the flow to the anterior spinal artery. If this condition is associated with both; post neuraxial blockade arterial hypotension or general anesthesia, an anterior spinal artery syndrome with definitive paraplegia may develop. An increased pressure in the intravertebral venous plexus (abdominal tumors, pregnancy, laparoscopic surgery) along with and obstruction of the artery can induce lumbar spinal cord ischemia. In vascular surgery; aortic clamping longer than 15 minutes, can cause paraplegia in up to one in 200 cases, when it is longer than 30 minutes, spinal ischemic injuries occur in up to $10 \%{ }^{1}$

Death and non-reversible paraplegia represent the two most feared catastrophic events in neuraxial anesthesia. Serious and permanent neurological complications are rare, even in the obstetric population, sometimes an undiagnosed meningioma can be the cause of spinal compression, however direct trauma after puncture and neurotoxicity are the origin of most neurological complications. ${ }^{4-6}$ Pre-existing deformities of the spinal canal, coagulation pathologies, poor aseptic technique, immunosuppression states and the presence of comorbidities are known to increase the risk of having a nerve injury after neuraxial block techniques. ${ }^{7-9}$ Neuraxial anesthesia, whether epidural, spinal or combined, has collateral effects and may present complications. There is a greater risk with combined spinal-epidural blockage as there is penetration into the subarachnoid space. ${ }^{10}$ It has been documented that the estimated prevalence of sensitivity and motor deficits after an event of neuraxial anesthesia ranges from $.005 \%$ to $0.7 \%$ some studies reporting an incidence of $0.13 \%, 0.12 \%, 0.03$ and $0 \%$ for epidural anesthesia. ${ }^{11-14}$

\section{CASE REPORT}

33-year-old male patient with no relevant medical history, suffers a femur fracture with a long oblique trace when practicing his hobby sport, causing pain and functional limitation for movements. $\mathrm{He}$ is evaluated in the Emergency Department by the Traumatology and Orthopedics service, finding a patient with swelling and deformation of the middle third of the right thigh with abduction and external rotation. Surgical resolution is determined, later assessed by the anesthesiology service who grants ASA 2 E2B surgical risk. Premedication with omeprazole, ondansetron, dexamethasone and neuraxial block at L2-L3 level, with intravenous sedation. The following anesthetic agents were used; heavy bupivacaine, fentanyl and continuous infusion pump for midazolam and fentanyl.

The femur fracture was reduced through open fixation placing an intramedullary nail with proximal and distal block pins. Shortly after finishing the surgery, the patient presented diminished strength in the upper and lower limbs, regaining strength in the upper limbs after 4 hours. During his postoperative follow-up, a decrease in strength was confirmed in the lower limbs with $0 / 5$ on the Daniels scale, $100 \%$ sensitivity without sphincter control, steroids were prescribed along with magnetic resonance imaging and a neurosurgical evaluation was requested. The MRI with the FFSE technique, shows bulging of the fibrous annulus that obliterates the epidural fat and makes contact with the thecal sac in the L5-S1 intervertebral disc level. Electromyography reports motor polyneuropathy of the pelvic limbs, axonal degeneration type without evidence of radiculopathy. The neurosurgery service prescribes rehabilitation sessions at home, electrostimulation and neuropathic medications.

Patient was discharged with rehabilitation sessions at home and medical treatment. During weekly follow-up, muscle hypotrophy is noted in lower limbs, limbs lift slightly using quadriceps with a score of $3 / 5$ for muscle strength. No movement was noted below the ankles, sensitivity was preserved with no sphincter control. In his last consultation, an evaluation from the psychiatry department was requested for ideas of disability, hopelessness, fantasies of death without a suicide plan related to limitations and loss of functionality. Patient does not return to external follow-up, cannot be located. 


\section{DISCUSSION}

Although regional anesthesia is relatively safe, it is not exempt of severe complications, the routine use of USG helps to determine the exact location of the desired space, to correctly measure the skin-epidural space distance. ${ }^{15,16}$ Permanent nerve injury secondary to neuraxial block is a rare but devastating complication.

The leading mechanisms of injury include: Direct trauma to the spinal cord by the needle and / or catheter, toxicity of the local anesthetic or its components. Compression of the spinal cord due to hematoma, tumor, vascular anomaly, bleeding disorders, anticoagulation pathologies, abscess (due to contamination in the puncture or hematogenous spread), idiopathic. Ischemia of the spinal cord caused by anterior spinal artery syndrome or vascular trauma. Neurological disease such as spinal meningioma, spinal arteriovenous fistula, intervertebral disc prolapse, Guillain-Barré syndrome, multiple sclerosis, tumor metastasis, thalassemia. ${ }^{10,17}$

In special situations when it is not possible to identify the mechanism of injury, MRI and a consultation from the neurosurgery department should be requested in order prevent any reinterventions. During the pre-anesthetic evaluation, the intentional search for known or unknown previous neurological deficit should be included, as well as a broad discussion of any complications with prolonged or permanent sequelae, including death. It is vital that the anesthesiologist has extensive and up-to-date knowledge of each and every one of the regional anesthesia techniques, the pharmacology of the drugs used, as well as knowing and being able to identify all possible complications.

Anesthesiology is ranked among the most potentially dangerous medical specialties for the patient and the anesthesiologist. Complications can happen with good doctors, performing the appropriate techniques and procedures and in the absence of negligence. ${ }^{1}$

\section{CONCLUSION}

Spinal cord injuries secondary to neuraxial block are very rare but present devastating consequences, sometimes leaving the patient permanent sequels. A multidisciplinary team must be assembled to attempt functional recovery and prompt biopsychosocial reincorporation.

\section{Funding: No funding sources}

Conflict of interest: None declared

Ethical approval: Not required

\section{REFERENCES}

1. Whizar-Lugo VM, Flores-Carrillo J.C. Complicaciones Neurológicas de la Anestesia Neuroaxial. Anestesia en México. 2006;18(3):13344.
2. Whizar LV, Carrada PS. Anestesia subaracnoidea. Cien años después. Rev Mex Anest. 1999;22:1-4.

3. Wong CA. Nerve injuries after neuraxial anaesthesia and their medicolegal implications. Best Practice \& Research Clinical Obstetrics and Gynaecology. 2010;24(2010):367-81.

4. Jedsadayoot S, Arpakorn K, Preeyaphan A. Paraplegia Following Obstetric Spinal Anesthesia: A Case Report. Biomed J Sci \& Tech Res. 2019;19(2):14229-31.

5. Auroy Y, Benhamou D, Bargues L, Ecoffey C, Falissard B. Major complications of regional anaesthesia in France: the SOS regional anaesthesia hotline service. Anesthesiology. 2002;97:1274-80.

6. Molina GMB, Borraz LP, Jose G-OL, RamirezFernandez A, Aliaga RM, Juan E-BJ et al. Neuraxial Anaesthesia Complications. Medical \& Clinical Reviews. 2015;1(4):1-7.

7. Hebl J. The importance and implications of aseptic techniques during regional anesthesia. Regional Anesthesia and Pain Medicine. 2006;31:311-23.

8. Wedel D, Horlocker T. Regional anesthesia in the febrile or infected patient. Regional Anesthesia and Pain Medicine. 2006;31:324-33.

9. Hewson DW, Bedforth NM, Hardman JG. Spinal cord injury arising in anaesthesia practice. Anaesthesia. 2018;73(1):43-50.

10. Domínguez-Gasca LG, Sandoval-Larios CG, LópezAlcalá LA, Hasslacher-Arellano JF, MoraConstantino J, Domínguez-Carrillo LG. Lesión del cono medular durante anestesia espinal: un diagnóstico clínico-radiológico. Acta Médica Grupo Ángeles. 2014;12(3):141-5.

11. Brown RA. Nerve damage following central neuraxial blockade: Is it avoidable? Rev Mex Anest. 2008;31(1):s56-61.

12. Horlocker TT, McGregor DG, Matsushige DK, Schroeder DR, Besse JA. A retrospective review of 4,767 consecutive spinal anesthetics: central nervous system complications. Perioperative Outcomes Group. Anesth Analg. 1997;84:578-84.

13. Auroy Y, Narchi P, Messiah A, Litt L, Rouvier B, Samii K. Serious complications related to regional anesthesia: results of a prospective survey in France. Anesthesiology. 1997;87:479-86.

14. Auroy Y, Benhamou D, Bargues L, Ecoffey C, Falissard B, Mer- cier FJ et al. Major complications of regional anesthesia in France: The SOS Regional Anesthesia Hotline Ser- vice. Anesthesiology. 2002;97:1274-80.

15. Loo CC, Dahlgren G, Irestedt L. Neurological complications in obstetric regional anaesthesia. International Journal of Obstetric Anesthesia. 2000;9(2):99-124.

16. Conroy PH, Luyet C, McCartney CJ, McHardy PG. Real-time ultrasound-guided spinal anesthesia: a prospective observational study of a new approach. Anesthesiol Res Pract. 2013;2013:525818. 
17. Sage DJ. Major neurological injury following regional anaesthe- sia, Complications of Regional Anesthesia. Edited by Finucane BT. Philadelphia, USA, Churchill Livingstone. 1999: 257-269.
Cite this article as: Cortés-Badillo LD, Reyes-

Gutiérrez A, Gómez-Chacón O, Olivera-León LD, Olivera-León ED, Granados-Romero JJ, et al.

Neuroaxial anesthesia caused paraplegia: a case report. Int J Res Med Sci 2021;9:1754-7. 